\title{
La portentosa vida de la Muerte, de fray Joaquín Bolaños: un texto apocalíptico y milenarista
}

\author{
por
}

\author{
Mercedes Serna Arnaiz ${ }^{1}$ \\ Universidad de Barcelona
}

\begin{abstract}
El presente ensayo tiene como objetivo desenmascarar las claves ideológicas de La portentosa vida de la Muerte, texto colonial del siglo XVIII, escrito por fray Joaquín Bolaños, un fraile franciscano nacido en Michoacán y afincado en México. Aunque el ensayo tiene como motivo principal plantear y demostrar la hipótesis por la cual esta obra-escrita a raíz de los sucesos y de los cambios sociales e históricos de finales del XVIII-, se vale del humorismo y del uso retórico del temor a la muerte como pretexto para moralizar y predicar con el fin de que la población lleve una vida honesta de acuerdo con los preceptos de la doctrina cristiana, apreciamos tras la escritura de su autor, un pensamiento apocalíptico cercano al joaquinismo o al milenarismo. Asimismo, recalamos en otros rasgos no menos importantes de La portentosa vida de la Muerte como la apología a la orden franciscana o el temor de su autor ante el racionalismo y el laicismo de la época.
\end{abstract}

PALABRAS ClaVE: milenarismo; apocalipsis; joaquinismo; predicación; franciscanismo; colegios de Propaganda Fide.

Cómo Citar este artículo / Citation: Serna Arnaiz, Mercedes, "La portentosa vida de la Muerte, de fray Joaquín Bolaños: un texto moralista, apocalíptico y milenarista", Revista de Indias, LXXVII/269 (Madrid, 2017): 115-136, doi:10.3989/revindias.2017.004.

\section{INTRODUCCIÓN}

La portentosa vida de la Muerte, emperatriz de los sepulcros, vengadora de los agravios del Altísimo, y muy señora de la humana naturaleza, impresa

1 serna@ub.edu ORCID iD: http://orcid.org/0000-0003-2385-0043. 
en México en $1792^{2}$, y escrita por el franciscano vecino de Zacatecas (perteneciente entonces a la Nueva Galicia) fray Joaquín Hermenegildo Bolaños, es un texto compuesto por 40 capítulos, un prólogo, un preámbulo, una conclusión y un testamento. Le acompañan dieciocho grabados atribuidos a Francisco Agüera. Su argumento es la historia novelada y episódica de la Muerte, y comienza, siguiendo el género épico e histórico, por su nacimiento y sus antecedentes, sigue con las peripecias de su vida y finaliza con su muerte. Se trata de un texto híbrido, tanto por lo que respecta al género en el que se inscribe - «novela», «protonovela», crónica, sermonario- como por los diferentes registros y materiales que utiliza en su composición (la sátira, la meditación, la imagen visual o el grabado), por el lenguaje (coloquial, chabacano, chusco, religioso o bíblico) o por el tono (solemne, trágico, cómico o grotesco). Su característica más peculiar es el trato irreverente de la Muerte, lo que le acerca a las tradicionales danzas de la muerte.

Algunos especialistas entienden que la censura e inquisición propias de la época obligaron a Bolaños a intensificar el tono eclesiástico en detrimento del carnavalesco, pero un estudio atento sobre la trayectoria vital del autor nos confirma, sin dudar, que éste se inscribe en el espíritu contrarreformista y en una línea de pensamiento que retrocedía al medievo, entre otros motivos, por el temor hacia una burguesía creciente que propiciaba una vida más mundana. Tras el ropaje de lo supuestamente humorístico y desenfadado como medio para divertir al lector y dulcificar la doctrina expuesta; y a pesar de que hay capítulos, como el décimo, de tono indudablemente satírico, descubrimos un fraile de espíritu conservador, que hábilmente encubre un pensamiento fundamentado en el orden antiguo. Como señala Claudio Lomnitz, este tipo de obras eran moralizantes y «los curas conservadores tenían el recurso al temor a la muerte como una estratagema para refrenar las pasiones del siglo» ${ }^{3}$. Así, el franciscano Joaquín Bolaños se valió del personaje de la Muerte, de quien ofrece un retrato a veces benévolo, otras, las más, ordinario, cruel y maledicente, para infundir el temor de Dios -el énfasis se pone en la imagen de la Muerte que llega de forma inesperada y se acerca con mala fe a su desprevenida víctima- y de este modo obligar a la población a llevar un comportamiento honesto.

La portentosa vida de la Muerte es una obra que, si no tiene un elevado valor estético -característica común de otros textos coloniales-, es interesan-

2 Agustín Yáñez, para su parcial edición de 1944, recoge los datos de la primera y única edición del libro, de 1792, y agradece a los señores Federico Gómez de Orozco y José Cornejo Franco la donación del ejemplar. Yáñez, 1994: XIX-XX.

3 Lomnitz, 2011: 256. 
te desde el punto de vista histórico, social y antropológico, porque además retrata el auge de la burguesía ${ }^{4}$, el terror ante el comienzo de la laicidad, las luchas eclesiásticas y la política colonial del momento. Pero hay una lectura críptica y escondida en La portentosa vida de la Muerte que sintoniza con el pensamiento apocalíptico, joaquinista y milenarista. Tal afiliación se manifiesta en el tono, la finalidad, los motivos y referencias de la obra, así como en la propia trayectoria vital del autor. Bolaños cita a Nabucodonosor, a los profetas ligados a la historia de Israel, se apoya continuamente en el Apocalipsis (en este sentido el último grabado iconográfico es también destacable), menciona «la sexta edad» y su leitmotiv es el temor al fin del mundo. Estos aspectos quedan encubiertos, de manera engañosa, por la aparente carnavalidad del texto. La escasez de referencias explícitas al milenarismo en la obra puede atribuirse tanto a la censura como a la autocensura. Como sabemos, buena parte de las crónicas de la conquista espiritual de América susceptibles de tener una lectura milenarista -las escritas por Motolinía, Mendieta, Zoritafueron confiscadas 5 .

Algunos datos de su biografía encajan bien con el pensamiento milenarista del autor, como el ser franciscano, un predicador incansable, formador de otros frailes y comentarista de las Sagradas Escrituras ${ }^{6}$, amén de dedicarse a la evangelización de los indios. Nacido en 1741, en Michoacán, se asentó en Cuitzeo de la Laguna, cabecera de dicho municipio, y tomó el hábito de la orden franciscana el 31 de agosto de 1765, en el convento de Guadalupe, Zacatecas. Nada se conoce de su vida hasta el momento en que se hizo fraile. El 2 de agosto de 1766 se ordena sacerdote en el mismo convento de Zacatecas. Es muy importante remarcar que, como apunta Blanca López de Mariscal $^{7}$, el convento de Guadalupe había sido fundado para convertirse en punta de lanza de la evangelización de los territorios del norte de la Nueva Galicia, una parte del Reino de León y la Nueva Vizcaya, misión que se recuerda en ocasiones en la obra. De esta manera, en el capítulo 8 de La portentosa vida de la Muerte se dice, de forma cruel, cómo ésta desea «poblar cuanto antes las colonias de la tierra adentro de cadáveres y esqueletos, para habitar y cultivar los países bajos» ${ }^{8}$. Hay que tener en cuenta que los «Países

${ }^{4}$ Francisco José López Alfonso aborda la influencia del auge de la burguesía en el pensamiento y la obra de Bolaños. López, 2009: 219-235.

5 Véase al respecto: Baudot 1983: 110. Duch, 1992: 112.

6 Sólo nos centramos en los aspectos biográficos que inciden en nuestra tesis. Para una mayor información sobre la biografía de Joaquín Bolaños, los estudios de Blanca López de Mariscal son fundamentales. López, 1992.

7 López, 1992: 12.

8 Ibidem: 142. 
Bajos», «Territorios del Norte» o «Tierra Adentro», eran rebeldes a la monarquía universal de los españoles. Por tanto, la labor de estos frailes era la de la predicación y conversión en un medio hostil en el que se jugaban la vida. En noviembre de 1766 Bolaños se encuentra en el Nuevo Reino de León, del que fue examinador sinodal del Obispado, una autoridad que examinaba a los que habían de ser admitidos en las órdenes o recibir títulos como el de párroco, confesor o predicador. Por tanto no cabe ninguna duda de que Bolaños era una autoridad y un referente en asuntos religiosos y eclesiásticos. Entre 1766 y 1784 hay un vacío biográfico pero, como señala Blanca López ${ }^{9}$, debió de dedicarse al estudio, por la erudición que muestran sus obras y, concretamente, la que nos atañe.

Nos hallamos ante un franciscano que posee las mismas señas de identidad que los primeros misioneros de dicha orden que llegaron con la conquista espiritual a México: es un predicador apostólico, al modo de los primeros discípulos, explica el evangelio y tiene la misión de catequizar, y, en el caso de Bolaños, de reducir religiosamente a las tribus guerreras del Norte de la Nueva España. Esta última tarea podría, además, presumiblemente estar relacionada con la obra que nos atañe, por cuanto existe la posibilidad de que $L a$ portentosa vida de la Muerte pudiera ser un manual de predicación, como ya advirtió Agustín Yáñez ${ }^{10}$, útil, incluso, para la interpretación de ciertos pasajes (de ahí su naturaleza de sermonario, tanto por el uso continuo de citas evangélicas como por la estructura de discurso que tiene dicha obra).

No es ocioso recordar que el libro está dedicado a Manuel María Trujillo, Predicador General, Teólogo, Reformador y Visitador de todas las provincias y Colegios de Indias; por lo tanto, no se nos escapa la finalidad política de La portentosa vida de la Muerte. En cualquier caso, con vistas a la predicación pudo ser de utilidad un libro que, además, incluía unos grabados de gran efectismo. Entre 1784 y 1785 -años en los que se cree que comenzó la redacción de La portentosa vida de la Muerte- se estableció en Monterrey. Allí convivió con el famoso obispo Rafael José Berger (o Verger), franciscano que había sido ordenado en Mallorca y conocido como el «obispo constructor» por la mejora que llevó a cabo en asuntos de infraestructura urbana, como la canalización y edificación de la ciudad de Monterrey o la construcción del palacio arzobispal en la Loma de la Vera. Bolaños tuvo que participar, junto con los otros franciscanos, en todos estos trabajos encabezados por el famoso

\footnotetext{
9 Ibidem: 13.

10 Agustín Yáñez señala en su prólogo a la selección antológica de La portentosa vida de la Muerte, de 1944, que la obra está «construida con vistas a la ejemplaridad, cuando no sea sin más un ejemplo tomado del repertorio convencional de los predicadores». Yáñez, 1994: VIII.
} 
obispo, tareas propias además de la orden franciscana, por su política a favor de las reducciones de indios. Por esta época, la ciudad recibía continuos ataques de los indígenas, que sembraban de terror y de miedo los caminos, en un clima, además, extremo.

Otro factor, ahora histórico, que pudo influir tanto en la génesis de esta obra como en la creencia de Bolaños de la llegada inminente del fin del mundo fue el clima de devastación que, a causa del hambre por las fuertes sequías, sufrió la población entre 1785 y 1786. Una de las crisis más severas de todo el siglo XVIII se produjo en el territorio en el que vivía Bolaños, tal como lo documenta Ortelli:

Según la información recopilada por Florescano, la gran crisis de 1785-1786 fue ocasionada por la confluencia de dos factores: el retraso de las lluvias en los primeros meses de la siembra y la sucesión de dos heladas excepcionalmente severas que destruyeron las cosechas en el centro, el occidente y el norte de Nueva España. Nuestras fuentes confirman que entre 1784 y 1786 se produjo un ciclo de sequía, pérdida de cosechas, escasez y hambruna. Saravia señala el ciclo 1784-1786 como un período de grandes pérdidas por la falta de lluvias y por una fuerte helada -absolutamente extraordinaria- que cayó el 27 de agosto de 1786 y destruyó por completo las sementeras. Corrobora esta situación una Memoria del obispo Esteban Lorenzo de Tristán, quien manifestaba: «Estrechó su justicia la necesidad y por los años continuos de 1784, 1785 y 1786 castigó a la Nueva Vizcaya con peste, hambre y guerra. Murieron la mitad de sus habitantes [...] Diariamente se enterraban en esta capital de veinte en veinte los muertos en medio de los campos y las haciendas». En las Gacetas puede leerse en 1785 que: «La escasez de semillas y por consiguiente el hambre azotaba a Durango, al grado que el cabildo eclesiástico se reservó un tercio de harina para hostias». Y, nuevamente, la pérdida de cosechas por heladas tempranas y escasez de lluvias en 1789, que las fuentes atestiguan en la sequía del período 1788-1789. En suma, se constata una concentración de referencias documentales relacionadas con el robo de animales en los momentos en que se registraron crisis de subsistencia. Esto es muy claro para 1771-1773 y 1784-1786, aunque en ambos momentos las autoridades coloniales explicaron el robo como consecuencia de las incursiones de los apaches, y estuvieron más preocupadas por la posibilidad de una rebelión que por la actividad de robo en sí misma. Si bien el robo era una actividad recurrente, es probable que durante las crisis de subsistencia el fenómeno se intensificara y saliera a la luz de manera más clara y evidente. Así, se detecta una correspondencia entre los momentos de sequía -reconocida en la documentación y la cronología de las fuentes- y las acciones de robo ${ }^{11}$.

Retrocediendo a la Edad Media, es de sobra conocida la tesis de que el miedo encuentra en los autos sacramentales, en las Ars moriendi, en los libros

11 Ortelli, 2010. 
de horas, danzas macabras, y danzas de la muerte, la expresión de un temor apocalíptico provocado por las guerras, las enfermedades, la pobreza, las plagas o la peste negra. Abundando en los ejemplos, debe citarse asimismo La dança general de la muerte, género propio en sí mismo, que es la expresión de una sociedad medieval asolada por la muerte en todos sus estratos. Por tanto es sensato argumentar que en el origen y fin de La portentosa vida de la Muerte, como en el espíritu milenarista de su autor, debió de influir este clima tan parecido al temor apocalíptico provocado por las guerras, las plagas y las enfermedades de la época medieval ${ }^{12}$. Bolaños acudió, ante los mismos sucesos catastróficos, a las mismas representaciones o discursos, si bien con algunas variaciones que dan originalidad y personalidad a la obra que nos ocupa.

\section{El espíritu franciscano en LA PORTENTOSA VIDA DE LA MUERTE}

La reforma de la orden seráfica, iniciada en 1496 por fray Juan de Guadalupe, fue llevada a México, con los primeros misioneros franciscanos, guiados por fray Martín de Valencia. Dicha reforma, como señala Baudot, «se presentaba como una interpretación más estricta de la regla franciscana, insistiendo en mayor austeridad y en mayor anhelo de pobreza evangélica» pero, sobre todo, "pretendía una renovación espiritual de muy altos vuelos reanudando con las esperanzas milenarias y las lecturas apocalípticas del fraile calabrés, Joaquín de Fiore, que conociera tanto prestigio en la Italia del siglo XIII» ${ }^{13}$. Las aspiraciones joaquinistas nutrieron a los franciscanos observantes de tal manera que éstos jugaron un papel preponderante en la iglesia española, a partir del siglo XVI ${ }^{14}$. El hecho de que la reforma del Padre Guadalupe se implantara al mismo tiempo que la conquista de México se interpretó de manera providencial. Como señala Baudot, «la familia seráfica tendría así la inmensa suerte de poder desempeñar un papel decisivo en la ordenación final de la humanidad, tal como la Sagrada Escritura la anunciara y tal como la historia del momento la ofrecía» ${ }^{15}$. Los franciscanos se dedica-

12 Así, sobre los orígenes de la danza de la muerte, Infantes considera que «fue la peste de 1348 la que dio forma literaria concreta a una serie de ideas, conceptos, temas y motivos repartidos por todo el continente» y que, buscando sus orígenes, debió retomar «un modelo primigenio», un «modelo literario tal vez latino» como el Vado Mori. Véase Infantes, 1997: 33-50 y 121 respectivamente.

13 Baudot, 1985: 11.

14 Ibidem: 14.

15 Idem. 
ron, bajo estos presupuestos, a la predicación y a la conversión como conquista espiritual y ante la creencia de la inminente llegada del fin del mundo.

El franciscanismo de primera hora se guio por los apóstoles en su intento de volver a los tiempos primitivos, basados en la pobreza y la predicación, con una visión utópica e idealista de la cristianización del indio. Esta época fue conocida como el «Siglo de Oro» de la evangelización. Los franciscanos de segunda hora, como Jerónimo de Mendieta, añoraron ese franciscanismo puro, heroico, de los tiempos antiguos, pues ellos vivían en un período de decadencia y decrepitud, «Edad de Plata» y catástrofe apocalíptica, parecido a la destrucción de Jerusalén por los babilonios. Como señala Phelan, a partir del siglo XVII existe una notoria declinación en la moral, la disciplina y la efectividad de los franciscanos de la Nueva España, en tanto en el siglo XVIII vuelven al entusiasmo evangélico con la esperanza de extender las fronteras ${ }^{16}$. Joaquín Bolaños se nos aparece, en esta obra, como un franciscano cercano a las ideas apocalípticas, muy crítico con la decadencia y decrepitud de la sociedad y que pretende volver a las virtudes y característica de la observancia franciscana de los primeros tiempos: un culto a la pobreza, no solo material sino también espiritual, una vuelta a la pureza, la moral y la disciplina de los tiempos primitivos, y un fuerte rechazo hacia la iglesia jerárquica en pro de la restauración de la iglesia originaria.

Dado el papel fundamental que los propios franciscanos se asignaron en la ordenación final de la humanidad, el objetivo común de los cronistas franciscanos en el Nuevo Mundo (fray Toribio de Benavente o Motolinía, Jerónimo de Mendieta, Diego Valadés y posiblemente el propio Bolaños) era dar fe de la extraordinaria labor de evangelización realizada por la orden seráfica frente a determinadas políticas opuestas a su ideario y misión, y temerosos ante su pérdida de poder. En este sentido el capítulo 36 de La portentosa vida de la Muerte es fundamental para darse cuenta de la dimensión política de la obra. En él, Bolaños hace gala abiertamente de su franciscanismo, concretamente de la predicación y el apostolado de los Colegios Apostólicos de Propaganda Fide, construidos «por voluntad del Altísimo que quería la conversión de innumerables pecadores de esta septentrional América» ${ }^{17}$, e iniciados, cuenta Bolaños, por el padre fray Antonio Linaz, de Michoacán.

Hay que recordar al respecto que en 1626 el franciscano Gregorio de Bolívar propuso a la congregación de propaganda Fide la creación de unos colegios seminarios en América con el fin de reclutar misioneros entre la población indígena. Proponía también que los educados en dichos colegios predicaran tanto

\footnotetext{
16 Phelan, 1972: 154

17 López, 1992: 326.
} 
en la iglesia como en las plazas ${ }^{18}$. En aquellos tiempos de grandes calamidades climatológicas y conflictos sociales, cabe señalar que la presencia evangelizadora más amplia era la de los franciscanos de la familia de la Observancia, interesados por la congregación de Propaganda Fide. Pretendían que cada obispado dispusiera de un colegio con personal dedicado a la predicación entre los infieles y pueblos cristianos. Especificaban también que la tercera parte de los sacerdotes fuera con destino a los pueblos de indios, que vivían sin presencia cristiana. A la sombra de la Propaganda Fide, los franciscanos crearon una nueva institución en el interior de la orden seráfica, empezando un proceso de evangelización acorde con lo expresado por el P. Gregorio Bolívar ${ }^{19}$.

Bolaños narra la vida de Linaz (recordemos que las hagiografías o biografías ejemplares son comunes en las crónicas espirituales, como las de Motolinía y Mendieta), hombre de éxito, catedrático, guardián del convento de Valladolid, prelado de ejemplar vida, cuya vertiginosa carrera le embebeció de tal forma que, desviándose de su camino, perdió sus aspiraciones religiosas en pro de la vanagloria. La Muerte, ahora una aliada del bien y actuando de buena fe, se presenta ante el fraile con la misma mortaja cenicienta con la que visten los religiosos en la provincia de Mallorca, lugar donde tomó el hábito nuestro fraile, y le recrimina su desvío con estas palabras:

A qué veniste a la orden seráfica?, o ¿para qué te trajo Dios a la religión del gran Francisco?, Dios te condujo a ella para que fueras luz del mundo, pero no luz para lucir, sino para alumbrar a los ciegos ${ }^{20}$.

Resulta obvia la incardinación de La portentosa vida de la Muerte en una propuesta de evangelización. Se trata de un texto apologético y propagandís-

18 Sobre el resurgimiento del fervor misionero de los franciscanos en la Nueva España debe consultarse la obra de Espinosa, 1746.

19 Formaron colegios para la preparación, continuidad o recambio de los misioneros. Las luchas eclesiásticas surgieron bien pronto lo que llevó a que, por la ley de Fernando VI de 1751, los franciscanos debieran dejar las doctrinas para entregarlas al clero secular. La institución de los Colegios de Propaganda Fide recogía el momento carismático de la historia franciscana en el continente latinoamericano. Los frailes ubicaban sus casas fuera de los límites de la plaza mayor, que podía también definirse territorio de extra muros. Pretendían testimoniar un mensaje evangélico y franciscano, que correspondía al vivir «sin nada de propio». La predicación, además, obligaba aprender las lenguas autóctonas. Los conflictos diversificaron la presencia franciscana, si bien siempre dentro la misma organización de la orden: la una conventual, otra de reducciones, y la última, la de las doctrinas. Remito a los estudios de Gómez Canedo, 1960. Sáiz Díez, 1992. Gonzaga, 1603. Es necesario un mayor acercamiento a las misiones franciscanas para comprender mejor La portentosa vida de la Muerte.

20 Ibidem: 329. 
tico de un proyecto misional, universal y ecuménico, que se concreta en los colegios Fide:

Este fue el apostólico varón promotor de la fundación del Colegio de la Santa Cruz de Querétaro, de donde salieron las erecciones de los Colegios Seminarios de Guatemala, Zacatecas y México para gloria de Dios, y bien de las almas, cuya portentosa vida podrá leer el curioso en la Crónica de los Colegios por el Reverendo Padre Fray Isidro Félix de Espinosa ${ }^{21}$.

La anécdota del padre Linaz no tiene una función meramente edificante o piadosa, sino que sirve para mostrar, desde una perspectiva franciscana, cómo debería ser la autoridad episcopal y religiosa, pues Bolaños considera que se ha degradado en mero poder. Asimismo, es una advertencia hacia los propios frailes franciscanos que se estaban desviando del camino en esos tiempos de pesimismo apocalíptico ${ }^{22}$, en pro de la vanagloria del mundo. El capítulo 3 es un buen ejemplo del estado deplorable en que Bolaños ve el mundo, donde ningún estamento se salva, ni el burgués, ni el civil, ni el eclesiástico. El autor critica sin reservas a la jerarquía eclesiástica que vive en el ocio, la codicia y la negligencia. Bolaños sigue la observancia franciscana en el culto a la pobreza y el rechazo hacia la iglesia jerárquica e institucional, a modo de los primeros misioneros franciscanos, cuya reforma espiritual de la Orden Seráfica, recordemos, además de proponer una interpretación más estricta de la regla franciscana, especialmente del voto de pobreza, estaría impregnada de un fuerte espíritu milenarista ${ }^{23}$.

Bolaños, a lo largo del texto arremeterá, en diversas ocasiones, contra el pecado de hibris o desmesura, uno de sus anatemas fundamentales. No hay que olvidar que el antiintelectualismo es un motivo franciscano que, según Le Goff ${ }^{24}$, puede deberse al rechazo del conocimiento entendido como una posesión que implicaba, además, el atesoramiento de libros, que en aquel momen-

21 Ibidem: 330.

22 Phelan al tratar de Jerónimo de Mendieta comenta cómo a finales del siglo XVI dicho cronista pasó de del optimismo al pesimismo apocalíptico, es decir, de una visión positiva de España como forjadora de la unidad espiritual de la humanidad, a una visión de total tristeza apocalíptica. Véase Phelan, 1972: 153. Bolaños, incluso, en esta visión pesimista, menciona la imagen del tiempo de las calamidades apocalípticas.

${ }^{23}$ Los primeros franciscanos, como Motolinía, cultivaron la pobreza, entendida como magna virtus e imitatio Christi; desarrollaron un fuerte rechazo hacia la Iglesia jerárquica e institucional, de la que desearon librar a la Nueva España y empezaron «a oír hablar de México como de la tierra prometida, destinada para la realización de una gran empresa». Véase Baudot, 1983: 251.

24 Le Goff, 2003: 128. 
to eran considerados objetos de lujo, y a la idea del saber como fuente de orgullo y dominación. Con el tiempo, la orden seráfica tuvo que ir admitiendo el componente intelectual para luchar contra las herejías y el libre pensamiento. Señalan al respecto Serna y Castany, al tratar el milenarismo en la Historia de los indios de la Nueva España de Motolinía, que «lo interesante es comprender que la Historia participa de esta relación ambigua con respecto del conocimiento» ${ }^{25}$. Esta misma ambigüedad persiste en Bolaños al tratar un tema tan incómodo como es el del probabilismo, en el capítulo 31 de la obra $^{26}$. En él, un moralista teólogo le pide a la Muerte su opinión sobre el probabilismo, pero esta pospone la respuesta. La crítica $^{27}$ del siglo XIX despreció La portentosa vida de la Muerte, entre muchas otras razones, por la actitud ambigua que muestra Bolaños ante este particular. En el capítulo siguiente, que como el anterior y no de forma ingenua también se ubica en París, la Muerte, cruel e injustamente, arrebata la vida de un joven que, ante una carrera brillante y con grandes aspiraciones intelectuales, no fue capaz de dejarlo todo para seguir a Cristo. Bolaños se muestra como un moralista exigente, que demanda del hombre acaso más que lo que éste es capaz de dar, aunque su pretensión final posiblemente no sea tanto la de castigar a este pobre joven como la de criticar el enciclopedismo y el racionalismo ${ }^{28}$. El

25 Serna y Castany, 2014: 56.

26 El probabilismo fue una doctrina teológica defendida por teólogos jesuitas que la propagaron por toda América y Europa. Inocencio XI la condenó en 1676. En el tiempo de Bolaños, el probabilismo quedó fuera de la discusión intelectual, desplazado por la fuerte irrupción del cientificismo y positivismo, con su búsqueda de verdades comprobables, que descartaba como un mero juego lo que se consideró un debate retórico sobre las opiniones probables. Bolaños posiblemente no fuera partidario del positivismo (éste creía en la fe demostrada frente a la fe revelada), ni querría enfrentarse a la Iglesia o defender una doctrina considerada ya anacrónica.

27 Agustín Yáñez, por ejemplo, en el prólogo que realizó para la selección antológica de La portentosa vida de la Muerte, de 1944, achaca a la obra todo tipo de defectos: una trama narrativa débil y convencional, accidental, «perdida frecuentemente bajo el aluvión doctrinario», «donde la ficción queda relegada», «la unidad es imposible»; el personaje de la Muerte es inconsistente «en la construcción de un carácter literario», «el afán de predicación destruye las últimas posibilidades que pudiera tener la conducción del asunto en planos semejantes a los de una novela» y donde el autor «mezcla sin gusto registros distintos, sentencias latinas y refranes del vulgo, notas de humor y disquisiciones soporíferas, paisajes alambicados y sermones gerundianos, hasta recaer en descuidos, chabacanerías, inepcias y disparates gramaticales». No obstante Yáñez apoya su parcial publicación «de una obra tan defectuosa» por el esfuerzo que representó «en pro de la novela criolla durante la colonia», «la lección que se desprende del análisis de los vicios y de lo frustráneo del esfuerzo, y el interés documental del libro». Yáñez, 1944: V-XX.

28 Sería interesante analizar todas las citas y referencias que aparecen en dicho capítulo pues son muy significativas. Por ejemplo, el autor cita, como referente negativo, a Juliano 
autor, exagerando irónicamente las aspiraciones del estudiante, arremete contra el triunfo del racionalismo y el cientificismo en la época (de ahí la ubicación de ambos capítulos), tal como también advierte Camacho ${ }^{29}$. Así satiriza Bolaños las aspiraciones de este joven:

Yo tengo ánimo de permanecer en París por el término de tres años, donde me graduaré de maestro en artes; después pasaré a Montpellier, haré mención por cuatro años, me impondré bien en la médica facultad: después pasaré a Bolonia en prosecución de la borla de jurisprudencia, pasado este tiempo le daré de mano al mundo abrasando la vida religiosa ${ }^{30}$.

Bolaños, en afinidad con los presupuestos doctrinales de la orden franciscana, arremete, una vez más, contra la vanidad y el pecado de soberbia.

\section{Apocalipsis y MILENARISMO EN LA PORTENTOSA VIDA DE LA MUERTE}

Con respecto concretamente al milenarismo en la obra de Bolaños, éste habría heredado dicha doctrina a través del espiritualismo franciscano que, tras haber sobrevivido de forma minoritaria y encubierta, habría renacido en España durante los siglos XV y XVI, gracias, en parte, a la figura del cardenal Jiménez de Cisneros, observante franciscano. No obstante, los estudios realizados por Bataillon ${ }^{31}$, Phelan ${ }^{32}$, Maravall ${ }^{33}$, Milhou ${ }^{34}$, Baudot ${ }^{35}$ o Gil, que

Augusto que, como sabemos, sus estudios filosóficos le llevaron a refutar el cristianismo y a restaurar el culto pagano. Dicha Refutación al cristianismo está hoy perdida.

29 Este tema ha sido también visto y tratado por José Manuel Camacho. En tanto Camacho entiende que esta actitud es propia de la época, «un antídoto barroco contra impíos y modernos», nosotros la relacionamos con el espíritu franciscano. Camacho, 2014: 99.

30 López, 1992: 302.

31 En 1957 Bataillón publica "Évangélisme et millénarisme au nouveau monde", donde relaciona a los franciscanos con Joaquín de Fiore y con la idea de que el fin de los tiempos era inminente. Bataillon, 1957: 25-44. Véase también, Bataillon, 1966: 807-831.

32 La obra de Phelan, 1972 -publicada originalmente en 1956- corresponde a uno de los estudios más relevantes para el análisis de la influencia del pensamiento joaquinista en América.

33 Maravall, 1974: 311-388. Tanto Bataillon como Maravall difieren acerca de la figura de Las Casas, en tanto el primero lo relaciona con la utopía milenarista (la Utopía, de Moro), el segundo con unas ideas más racionales y secularizadas que las del providencialismo franciscano.

34 Milhou analiza la empresa colombina del descubrimiento en el marco de las manifestaciones político-religiosas de su época y las corrientes mesiánicas y milenaristas de las órdenes mendicantes, especialmente la de los franciscanos. Milhou, 1983.

35 Baudot, 1983. 
consagraron la teoría que ve en la acción de los franciscanos en el Nuevo Continente un cometido y ejecución del milenarismo medieval y bíblico, han sido rebatidos por historiadores como Alonso del Val ${ }^{36}$, Gómez Canedo ${ }^{37} \mathrm{o}$ María Concepción Bravo, quien, en su "Milenarismo y resistencia cultural en la historia de los pueblos andinos", critica que se ha tendido a asociar la idea del milenarismo con la ideología judeo-cristiana exclusivamente, pero que en el caso americano, en general, y del andino, en particular, demuestra que esto no es asín 38 .

Es difícil diferenciar conceptos tan estrechos entre sí como milenarismo, joaquinismo, apocalipticismo o escatologismo e incluso utopismo. Sin embargo, como señalan Serna y Castany, puede decirse que el franciscanismo o algunas corrientes cristianas del siglo XVI tuvieron convicciones milenaristas y que fueron propias del «espíritu de la época» " ${ }^{39}$. El milenarismo tuvo brotes y rebrotes a lo largo de la historia, sobre todo a finales del siglo XII cuando el monje calabrés Joaquín de Fiore ${ }^{40}$ (1135-1202) estableció un nuevo sistema profético según el cual la historia del mundo se dividiría en tres «edades» de pureza creciente, en la última de las cuales una orden monástica-que muchos identificaron con la orden seráfica- había de dirigir a una humanidad purificada a la espera del fin del mundo. El joaquinismo será la teología de la historia que, como afirmará Norman Cohn, «mayor influencia ejerciera en Europa hasta la aparición del marxismo» ${ }^{41}$.

La portentosa vida de la Muerte tiene un cierto aire, si no declaradamente milenarista, sí apocalíptico, muy en sintonía con el espíritu franciscano. Bolaños cita fuentes bíblicas milenaristas (Daniel, Isaías, Jeremías, Apocalipsis), parece obsesionado por el tema del pecado y la conquista de Jerusalén, menciona «la sexta edad», y su leitmotiv es la llegada del fin del mundo.

36 Alonso del Val critica a Bataillon, Phelan, Maravall, Milhou y señala que si bien el franciscanismo pudo verse influido por Joaquín de Fiore, de éste no puede afirmarse que fue milenarista. Alonso del Val, 1998: 365-382.

37 Gómez Canedo discute sobre la relación milenarismo, escatología y utopía, desarrollada en los trabajos de Phelan, 1956 y Baudot, 1983. Se exponen los principales errores de ambos autores en relación a la lectura milenarista del pensamiento de figuras de la primera etapa de la evangelización en América, tales como Zumárraga, Motolinía y Mendieta. Gómez Canedo, 1993.

38 Bravo, 2009: 268.

39 Serna y Castany, 2014: 50-70.

40 Sobre la influencia de Joaquín de Fiore en la teología americana: http://www.franciscanos.net/medieval/varios/joaquin\%20de\%20fiore\%20en\%20amer\%20latina.htm. También sobre el milenarismo en Fiore: http://www.scielo.cl/scielo.php? pid=S0049-34492003000200 $007 \&$ script $=$ sci_arttext.

41 Cohn, 1972: 115. 
La misma obra puede ser considerada como un relato de los signos anunciatorios y preparatorios del fin de los tiempos. Vale decir que no hay en ella ninguna referencia explícita al milenarismo, aunque ello podría atribuirse, como hemos indicado más arriba, tanto a la censura como a la autocensura. No hay que olvidar que el Papa Juan XXII había condenado, ya desde 1317, el movimiento de los «espirituales» franciscanos, para ordenar, seis años más tarde, su completa disolución, si bien el espiritualismo y el joaquinismo continuaron existiendo en los márgenes y fueron muy influyentes en movimientos populares de flagelantes, fraticelos, begardos, beguinas $\mathrm{y}$, finalmente, en el movimiento franciscano de los observantes ${ }^{42}$.

La portentosa vida de la Muerte insinúa motivos milenaristas y apocalípticos asociados al franciscanismo pero no los expresa exhaustivamente, como tampoco lo hicieron sus maestros y antecesores de la orden en sus crónicas. No podemos afirmar que Bolaños crea en la instauración del reino de Dios en la tierra, pero sí se hace eco del cercano fin de los tiempos.

La escatología milenarista estuvo presente, como hemos señalado, en el desarrollo de la empresa colonizadora de América desde sus inicios. Algunos autores, como J. L. Phelan y Georges Baudot, afirman que el proyecto de evangelización de los religiosos franciscanos para América Latina puede ser catalogado como milenarista, afirmación que fundamentan al decir que dichos religiosos acogieron las ideas de Joaquín de Fiore y al depositar sus esperanzas en la edificación de un reino milenario en América; sin embargo, parece que tales afirmaciones, como señalan Serna y Castany, tienen su origen en una confusión al no distinguir con claridad entre milenarismo y escatología cristiana $^{43}$. Sea como fuere, lo que sí puede afirmarse es que el milenarismo en sus varias facetas ha estado presente en América Latina desde los inicios de la colonización.

Existen varios pasajes de la obra de Bolaños que parecen evidenciar cierto interés o afinidad por el imaginario milenarista. El autor se olvida, progresivamente, de dorar la píldora a través del humor, y se acerca, en los últimos capítulos, a un discurso de tono más milenarista y terrorífico, ante la inminente llegada del Salvador y la falta de preparación del pueblo. En el capítulo 38 se advierte de que la Muerte se asomará por la ventana de un sepulcro para ver el día del Juicio Final y se relata lo que le sucederá, asimismo, a la propia Muerte. Ese día de la segunda venida de Cristo, la Muerte estará aturdida, espantada, desamparada y huirá de los hombres. En el capítulo 39, el autor informa de la llegada de unas señales funestas y espantosas que anun-

\footnotetext{
42 Alonso del Val, 1998: 370.

43 Serna y Castany, 2014: 45.
} 
ciarán por el orbe el fallecimiento de la Muerte y del mundo mismo. Bolaños avisa que «estas prodigiosas señales no son otra cosa que unos síntomas mortales, que declaran estar el mundo muy próximo a agonizar, y también la Muerte, porque hasta la Muerte ha de acabar» ${ }^{44}$.

El autor se guía por presagios infaustos, aun reconociendo que el padre Feijóo los desecha por infundios. Refiriéndose a la señal de la resurrección de la carne y al juicio final del Apocalipsis, recalca que todo será espantoso «y se dejará sentir por la vasta región de los sepulcros el sonido de una horrible trompeta, como cuando tocan a juntar hombres a juicio, y se estremecerán las bóvedas subterráneas y los sepulcrales edificios» ${ }^{45}$.

En el capítulo 40 relata la senectud de la Muerte y principio de sus agonías. El autor cita ahora los evangelios y a sus comentaristas más ilustres para señalar con ellos que la segunda venida de Cristo se producirá entre las once de la noche y la una de la mañana y comenta las distintas exégesis bíblicas que existen con relación a la llegada de Cristo. Seguidamente afirmará que «el mundo cuenta ya seis edades ${ }^{46}$.

Como sabemos por Flori, las religiones prometen una vida feliz y eterna en el Reino de Dios que se establecerá en el fin de los tiempos. Así, «el fin del mundo no es una catástrofe, sino que marca el término de la historia humana -llena de sufrimientos- y el inicio de una felicidad eterna» ${ }^{47}$. Se trata, pues, de la realización de una esperanza, particularmente para los infelices -pobres, débiles, enfermos, marginados-, que esperan la justicia de Dios, esto es, la recompensa para los «buenos» y el «castigo de los malvados» ${ }^{48}$. Por eso el fin de los tiempos está siempre seguido de un «Juicio final», que evidenciará el destino eterno de cada uno. El sentimiento es ambiguo, trágico, al mismo tiempo esperanzado y aterrorizado. Al fin y al cabo, en la Biblia, el fin de los tiempos viene tras una época marcada por sucesos terribles: inundaciones, persecuciones, guerras o masacres. El ambiente en el que vive Bolaños no puede ser más similar al descrito.

La portentosa vida de la Muerte podría entenderse, en esta lectura milenarista, como un texto hermenéutico de exégesis e interpretación escatológica de la Biblia. Es casi imposible rastrear las múltiples citas bíblicas en que se apoya el texto y a sus exegetas más conocidos, de los que se nutre nuestro autor, pero sí que puede concluirse que Bolaños nombra muy especialmente

\footnotetext{
${ }^{44}$ López de Mariscal, 1992: 349.

45 Idem.

46 Idem.

47 Flori, 2008: 7.

48 Idem.
} 
los libros de Daniel ${ }^{49}$ y el Apocalipsis que son los que ofrecen la base fundamental de las profecías que conciernen al fin del mundo. De igual manera, alude a otros menos proféticos. No es ocioso señalar aquí que Joaquín de Fiore dedicó su vida al estudio de las Escrituras tratando de captar lo que él creía su verdadero significado, estableciendo correspondencias entre el Antiguo y el Nuevo Testamento. Se interesó sobre todo por las profecías, en particular las del Apocalipsis, del que escribirá un comentario iniciado en 1184, numerosas veces refundido y reescrito. En su Libro de la concordancia pone en evidencia una correspondencia entre las fases mayores de la historia del pueblo judío y las de la Iglesia hasta el fin de los tiempos. Esta correspondencia, erigida en sistema, le permitió exponer una verdadera teología de la historia ${ }^{50}$.

Como ya hemos dicho, para Joaquín de Fiore la historia del mundo se divide en tres «edades» de pureza creciente. Para conocer el desarrollo del plan de Dios en la Historia, interroga las Escrituras, en las que establece correspondencias a la vez místicas e históricas entre las tres edades. Cada edad se divide en siete períodos que corresponden a los siete sellos del Apocalipsis. Los acontecimientos narrados en la Biblia están destinados, si se les interpreta correctamente, a enseñar y advertir por la historia, puesto que lo que le sucedió al pueblo judío en la primera edad prefigura lo que le sucederá a la Iglesia en la segunda, y también lo que sucederá en la tercera edad, en el fin de los tiempos, que se acercaba a la época en la que escribía el beato ${ }^{51}$. En su análisis histórico de las profecías de Daniel y del Apocalipsis, Joaquín de Fiore retoma la interpretación tradicional de los primeros siglos. La actualiza poniendo el acento sobre la potencia sarracena, muy presente en su pensamiento. Ocupa el lugar, de algún modo, del imperio romano en la interpretación antigua. Toda la historia profética bíblica tiende, pues, a anunciar los acontecimientos que van a preceder ese fin de los tiempos. La interpretación joaquinista fue pronto expuesta bajo la forma de dibujos comentados, dibujados quizás por la mano de Joaquín de Fiore en El libro de las figuras ${ }^{52}$. La persecución del último Anticristo -que pensaba que iba a aparecer pronto, puesto que ya había nacido- sería precedida por una predicación del Evangelio en el mundo entero, lo que conllevaría conversiones masivas. Esta predi-

49 Elsa Cecilia Frost (1976: 3-26), a partir de una contextualización del libro de Daniel en la literatura apocalíptica, aborda la interpretación milenarista que los frailes minoritas en Nueva España desarrollaron del sueño de Nabucodonosor y de otras profecías testamentarias.

50 Flori, 2008: 18.

51 Ibidem: 108.

52 Ibidem: 110. 
cación sería cumplida por monjes predicadores. Los franciscanos se considerarían esa orden ${ }^{53}$. Esta interpretación es amplificada por sus discípulos posteriores y por una gran parte de los franciscanos que, a imitación de San Francisco, propondrán una alternativa a la cruzada: la predicación hasta el martirio. Una tarea que deberán cumplir por la pureza de su vida. Estos misioneros «espirituales» debían haber anunciado el Evangelio en todas las naciones antes de que llegara el fin, marcado por la conversión de los judíos $\mathrm{y}$ de los infieles.

No es forzado establecer vinculaciones entre las ideas joaquinistas y las de nuestro autor. Bolaños, como Joaquín de Fiore, dedicó muchos años de su vida, como hemos comentado en el apartado biográfico, al estudio de las Escrituras y claramente se interesó muy especialmente por los libros proféticos. Bolaños se vale de las Escrituras y de sus intérpretes para conocer el desarrollo del plan de Dios en la historia, aunque no lo hace tan abiertamente como Joaquín de Fiore. Cree, como éste, que los acontecimientos narrados en la Biblia están destinados, si se interpretan correctamente, a enseñar y advertir, con el fin de estar preparados en cualquier momento, y es por ello que en la narración de los sucesos bíblicos pone el acento en las premoniciones o presagios previos a los castigos divinos.

Bolaños, además, siguiendo el espíritu de su orden, entiende que la predicación es la mejor cruzada antes de la llegada del fin de los tiempos. Incluso, temáticamente, La portentosa vida de la Muerte podría tener un significado escatológico parecido al milenarismo joaquinista, pues hay tres temas que destacan fundamentalmente. El primero (primera época de la historia propuesta por Joaquín de Fiore) corresponde al Antiguo Testamento o Edad de Dios, identificado con la idolatría y la itinerancia de los israelitas. El segundo, a los esfuerzos de la predicación y la posibilidad de salvación de la humanidad (recordemos que en La portentosa vida de la Muerte se dice que ésta pretende «poblar cuanto antes las Colonias de Tierra adentro»); el tercero, a la Edad del espíritu o reino milenario, con el inminente fin y la segunda llegada de Cristo.

El autor está obsesionado, especialmente, por el primer tema, encarnado en la caída de Jerusalén. Una y otra vez habla del pecado de Jerusalén o lo retoma a través de distintos exegetas bíblicos. Bolaños rastrea la Historia Antigua, la Biblia Vulgata, el libro de los Proverbios de Salomón, el Eclesiástico y el Eclesiastés. Narra los hechos del séptimo rey de Israel que procuró la destrucción de todos los profetas de Jehová, del malvado Acab, de Samuel, de Saúl, del primer rey de Israel o de los filisteos (173-175), y lo hace sin

53 Ibidem: 112. 
seguir un orden cronológico. Por ejemplo el capítulo 13 está dedicado a Nabucodonosor (rey de Babilonia desde 605 hasta 562 a.C., que, en 562, atacó Judá, sitió y venció a Jerusalén y se apoderó de los tesoros de su templo), y a su hijo Baltasar, último rey de Babilonia. El siguiente está dedicado al castigo que cayó sobre el pueblo de Israel por culpa de la envidia que se desata en Satanás por las glorias del rey David ${ }^{54}$. Seguidamente, se dice, no obstante, que Dios envió una peste a Israel y cayeron entre los israelitas setenta mil hombres (Paralipómenos) ${ }^{55}$. A continuación, el autor menciona la historia de Ezequías (duodécimo rey de Judá, que consiguió, por intervención divina, destruir al ejército asirio) y de Isaías, uno de los grandes profetas de Israel, del siglo VIII. En el capítulo 34, retoma el tema de la ingrata Jerusalén, que acabó sepultada cumpliendo el vaticinio funesto.

Ciertamente, este asunto se vuelve obsesivo en Bolaños y, si bien puede parecer que a partir de la segunda parte del libro cita más a los evangelistas, Lucas, Mateo (las trompetas en relación con la segunda venida de Cristo y el juicio final) o San Pablo, vuelve los ojos, una y otra vez, al Apocalipsis de San Juan, a la historia de David y a los autores de los libros proféticos del Antiguo Testamento.

Bolaños se guía, paralelamente, por exégetas e intérpretes de las Escrituras para desentrañar el verdadero significado de la Historia, como Juan Esteban Menochio, Cornelio a Lápide, Nicolás de Lira o filósofos platónicos como Porfirio. No cabe duda de que el autor pretende, como buen predicador, recordar el pecado para no pecar, pero también darles a conocer el plan divino de la Historia.

El autor utiliza el método de datación absoluta cuando al final de la obra señala:

El mundo cuenta ya seis edades y desde que salió de los brazos de la omnipotencia, hasta la presente época, numera seis mil novecientos noventa y años, según el cómputo cronológico del Martirologio Romano ${ }^{56}$.

En la Biblia no hay ninguna alusión profética a un modo de fijar la fecha del fin del mundo. Por lo tanto, desde la primera mitad del siglo II, algunos autores cristianos piensan poder evaluar la duración de la existencia acordada al mundo presente apoyándose, sacándola de su contexto, sobre la frase poé-

\footnotetext{
54 López de Mariscal, 1992: 187.

55 Ibidem: 191.

56 Ibidem: 353.
} 
tica de un salmo ${ }^{57}$ citado en la segunda carta de Pedro. Esta metáfora no tenía ninguna intención de orden cronológico, pero su uso, ligado a la evocación de la semana creadora, hizo nacer una interpretación exegética, cuanto menos azarosa y paradójica, que condujo a una «cronología absoluta». Ésta entra en concurrencia con las «cronologías relativas» que se apoyaban sobre los signos apocalípticos.

Hallamos desde el siglo II hasta el corazón de la Edad Media muchos testimonios de la creencia de que el mundo durará seis mil años (Epístola de Seudo-Bernabé, Hipólito de Roma, Ireneo de Lyon, Lactancio). Según Rus$\mathrm{so}^{58}$, citado por Duch ${ }^{59}$, en muchos autores franciscanos primitivos «se convirtió en un tópico identificar a san Francisco con el ángel del sexto sello del Apocalipsis, que en la hipótesis joaquinista anunciaba la nueva era» ${ }^{60}$. Las manifestaciones inexplicables (cometas, signos celestes o nacimientos de animales monstruosos) toman entre los hombres una connotación apocalíptica. El número elevado de signos astronómicos mencionados entre 950 y 1050 y, particularmente, entre 1000 y 1009, ofrecía argumentos para sostener la siempre postergada inminencia de la llegada del fin de los tiempos. En su obra, Bolaños hace constante alusión a los cometas, a las premoniciones y signos celestes.

Como conclusión, hemos destacado, en primer lugar, el fuerte espíritu franciscano de La portentosa vida de la Muerte. El franciscanismo se inició en el mundo americano con la llegada y asentamiento de los primeros «doce» misioneros de dicha orden llegados a México. Estos pusieron en marcha, en suelo mexicano, la reforma de San Gabriel, que propugnaba una vida más acorde con el primitivismo cristiano, caracterizada por la pobreza, como magna virtud, la predicación evangélica y el rechazo a la iglesia jerárquica. Este espíritu misionero de la primera edad, denominada también como el «Siglo de Oro» de la evangelización, fue continuado por otros cronistas y franciscanos misioneros como Jerónimo de Mendieta, Diego Valadés o Joaquín Bolaños.

57 Salmo 90, 4:

En verdad, mil años, para ti,

son como el día de ayer, que pasó.

¡Son como unas cuantas horas de la noche!

58 Russo, 1975: 35.

59 Duch, 1992: 308.

60 Así lo señalan, igualmente los autores que aparecen a continuación. Lambert, 1986: 210. Reeves, 1969: 147. Simoni Balis-Crema, 1976: 145-179. Saranyana y Beascochea, 1990: 173-189. Lambert, 1986. Reeves, 1969. Según explica Duch (1992: 308), Bartolomé de Pisa interpreta el novus ordo joaquinista, la tercera edad, entendiendo a los franciscanos como los pregoneros del nuevo evangelio (cf.: Russo, 1975, I: 129-141). 
Este último posee las mismas señas de identidad que los primeros misioneros de su orden que llegaron a México: es un predicador apostólico, al modo de los primeros discípulos, y cree en el papel mesiánico de la orden franciscana, que entiende que la predicación es la mejor cruzada antes de la llegada del fin del mundo.

En segundo lugar, entendemos que Bolaños se hace eco de un pensamiento apocalíptico y milenarista, heredado a través del espiritualismo franciscano, el cual, tras haber sobrevivido de forma minoritaria y encubierta, habría renacido en España durante los siglos XV y XVI, gracias, en parte, a la figura del cardenal Jiménez de Cisneros, observante franciscano. Nos apoyamos en nuestra tesis en la teoría que ve en la acción de los franciscanos en el Nuevo Continente un cometido y ejecución del milenarismo medieval y bíblico, apocalíptico y milenarista encarnado, cronológicamente, en las obras de Motolinía, Mendieta y, en nuestra opinión, Bolaños. Nuestro autor pertenecería a los franciscanos que, como Jerónimo de Mendieta, añoraron el franciscanismo primitivo, puro, heroico, de los tiempos primitivos, pues, por el contrario, ellos sentían que vivían en un tiempo de decadencia y decrepitud, «Edad de Plata» o catástrofe apocalíptica, parecida a la destrucción de Jerusalén por los babilonios.

Siguiendo el nuevo sistema profético de Joaquín de Fiore, según el cual la historia del mundo se dividiría en tres «edades», los franciscanos se dedicaron a la predicación y a la conversión como conquista espiritual y ante la creencia de la inminente llegada del fin del mundo. Así, aunque aparentemente el objetivo fundamental de La portentosa vida de la Muerte es inducir el temor a la muerte para que la población tenga un comportamiento honesto y siga los preceptos católicos, hay un interés personal por parte de Bolaños de captar el verdadero significado de las Escrituras, a imitación de Joaquín de Fiore, a través de los libros proféticos o del Apocalipsis de San Juan, y más concretamente de los textos que nos remiten a la primera edad, y siguiendo la división establecida por Joaquín de Fiore. La finalidad de esta exégesis bíblica realizada por Bolaños no es tan solo la de adivinar el plan divino de la Historia, plan en el que la caída de Jerusalén es un pieza fundamental, sino conocer cuándo se producirá la inminente venida de Cristo. Es por ello que abundan en el libro imágenes o resonancias escatológicas como «hora sexta» o «el mundo cuenta ya seis edades». Premoniciones, advertencias y avisos funestos, con manifestaciones inexplicables, alusiones proféticas y signos apocalípticos, de que la nueva era estaba por llegar. 


\section{BIBLIOGRAFÍA}

Alonso del Val, José María, "El milenarismo en la primera evangelización de los franciscanos en América", José Ignacio de la Iglesia Duarte (coord.), Milenarismo y milenaristas en la Europa medieval: IX Semana de Estudios Medievales, Nájera, Instituto de Estudios Riojanos, 1998: 365-382.

Bataillon, Marcel, "Évangélisme et millénarisme au nouveau monde", Courants religieux et humanisme à la fin du XVe et au début du XVIe siècle, colloque de Strasbourg, Paris, Presses Universitaires de France, 1957: 25-44.

Bataillon, Marcel, Erasmo y España. Estudios sobre la historia espiritual del siglo XVI, México, FCE, 1966 [1937].

Baudot, Georges, Utopía e Historia en México: Los primeros cronistas de la civilización mexicana (1520-1569), Madrid, Espasa-Calpe, 1983.

Baudot, Georges (edición, prólogo y notas), Historia de los indios de la Nueva España, Madrid, Castalia, 1985.

Bravo Guerreira, María Concepción, "Milenarismo y resistencia cultural en la historia de los pueblos andinos", Destiempos, III/18 (México D.F., 2009): 268-286.

Camacho, José Manuel, "Entre el sermón y la ficción. Estrategias narrativas de la portentosa vida de la muerte (1792) de Joaquín Bolaños", Narrar lo imposible. La crónica indiana desde sus márgenes, Madrid, Verbum, 2014: 99-139.

Cohn, Norman, En pos del milenio. Revolucionarios, milenaristas y anarquistas místicos de la Edad Media, Barcelona, Barral, 1972.

Duch, Lluís, La memòria del sants: El projecte dels franciscans a Mèxic, Barcelona, Publicacions de l'Abadia de Montserrat, 1992.

Espinosa, Isidro Félix de, Crónica de los colegios de Propaganda Fide de la Nueva España, México, 1746.

Flori, Jean, La fin du monde au Moyen Âge, Paris, Gisserot-Histoire, 2008.

Frost, Elsa Cecilia, "El milenarismo franciscano en México y el profeta Daniel", Historia Mexicana, XXVI/1 (México, 1976): 3-26.

Gómez Canedo, Lino, "Los orígenes franciscanos en Colombia (1594-1565)", Archivum Franciscanum Historicum, 53 (Madrid, 1960): 1-79.

Gómez Canedo, Lino, "Milenarismo, escatología y utopía en la evangelización de América", Evangelización, cultura y promoción social. Ensayos y estudios críticos sobre la contribución franciscana a los orígenes cristianos de México (Siglos XVI-XVIII), México, Porrúa, 1993: 1.399-1.409. 
Gonzaga, Francesco, De origine Seraphicae Religionis..., Venetiis, typographia Dominici Imberti (IS), 1603.

Infantes, Víctor, Las danzas de la muerte. Génesis y desarrollo de un género medieval, Salamanca, Universidad de Salamanca, 1997.

Lambert, Malcolm D., La herejía medieval: Movimientos populares de los bogomilos a los husitas, Madrid, Taurus, 1986.

Le Goff, Jacques, San Francisco de Asís, Madrid, Akal, 2003.

Lomnitz, Claudio, Idea de la muerte en México, México, FCE., 2011.

López Alfonso, Francisco José, "Literatura, religión y sociedad: De La portentosa vida de la Muerte a Don Catrín de la Fachenda", Temas y variaciones de Literatura, semestre 1/32 (México D.F., 2009): 219-235.

López de Mariscal, Blanca (edición crítica, introducción y notas), La portentosa vida de la Muerte, de fray Joaquín Bolaños, México, Colegio de México, 1992.

Maravall, José Antonio, "Utopía y primitivismo en el pensamiento de las Casas", Revista de Occidente, II (Madrid, 1974): 311-388.

Milhou, Alain, Colón y su mentalidad mesiánica en el ambiente franciscanista español, Valladolid, Seminario americanista de la Universidad de Valladolid, 1983.

Ortelli, Sara, "Crisis de subsistencia y robo de ganado en el septentrión novohispano: san José del Parral (1770-1799)", Relaciones, XXXI/121 (Zamora, 2010): 21-56.

Phelan, John L., El reino milenario de los franciscanos en el Nuevo Mundo, México, Universidad Nacional Autónoma de México, 1972.

Reeves, Marjorie, The Influence of Prophecy in the Later Middle Ages: A Study in Joachimism, Oxford, Oxford University Press, 1969.

Russo, Francesco, "Gioachinismo e Francescanismo", Joachim of Fiore in Christian Thought, Nueva York, D.C. West, 1975: 129-141.

Sáiz Díez, Félix, Los Colegios de Propaganda Fide en Hispanoamérica, Lima, Ceta, 1992. Segunda edición.

Saranyana, Josep-Ignasi y Beascochea, Ana de Zaballa, "La discusión sobre el joaquinismo novohispano en el siglo XVI en la historiografía reciente", Quinto Centenario, XVI, 1990: 173-189.

Serna, Mercedes y Castany, Bernat (introducción, notas y edición), Historia de los indios de la Nueva España de Fray Toribio de Benavente, Madrid, RAE, 2014.

Simoni Balis-Crema, Fiorella, "Gli spirituali tra gioachimismo e responsabilità escatologica", Chi erano gli spirituali, Atti del III Convegno Internazionale, Assisi, 16-18 octubre, 1975, Asís, 1976: 145-179. 
Yáñez, Agustín, "Prólogo" a Francisco Bramón, Los sirgueros de la Virgen y Joaquín Bolaños, La portentosa vida de la Muerte, México, D.F., Ediciones de la Universidad Nacional Autónoma de México, Biblioteca del estudiante universitario, 1944: V-XXII. Segunda edición.

Fecha de recepción: 12 de febrero de 2015.

Fecha de aceptación: 18 de abril de 2015.

\section{Fray Joaquín Bolaños's La Portentosa Vida de la Muerte: an apocalyptic millenarian text}

This essay explores the ideological basis for La Portentosa Vida de la Muerte, an eighteenth-century colonial text written by a Franciscan monk resident in Mexico. The study shows that this work, written in the wake of the social and historical changes of the late eighteenth century, draws on humor and makes rhetorical use of the fear of death as a pretext for moralizing, preaching and urging readers to lead an honest life in accordance with the precepts of Christian doctrine. However, the study also stresses that underlying Bolaños' text is an apocalyptic line of thought that is close to Joachimism or millenarianism. Equally important features of the La Portentosa Vida de la Muerte are also discussed, including its apologia for the Franciscan Order and the author's fear of the rationalism and secularism of the time.

KeY WORDS: millenarianism; apocalypse; Joachimism; preaching; the Franciscan Order; Propaganda Fide schools. 